\title{
PKM: Diversifikasi Produk Jamu Serbuk Instan Dari Herbal Usadha Bali Pada Kelompok Sari Pertiwi Desa Nyalian Kecamatan Banjarangkan
}

\author{
Ni Made Dwi Yunica Astriani*1, I Komang Gde Trisna Purwantara ${ }^{2}$, Siti Maryam ${ }^{3}$ \\ ${ }^{1}$ Prodi Profesi Ners STIKes Buleleng; ${ }^{2}$ Prodi S-1 Keperawatan STIKes Buleleng; ${ }^{3}$ Jurusan Kimia \\ FMIPA Undiksha \\ *Penulis Korespondensi, Ni Made Dwi Yunica Astriani, Prodi Profesi Ners STIKes Buleleng \\ Email : astrianiyunica1@gmail.com
}

\begin{abstract}
ABSTRAK
PKM kelompok Sari Pertiwi yang merupakan industri jamu tradisional yang berlokasi di banjar Kelodan desa Nyalian kecamatan Banjarangkan kabupaten Klungkung-Bali adalah jamu SIRKUMA yang terbuat dari campuran kunyit, temulawak, jahe merah, kencur, daun sirih, daun pegagan, buah pinang, lemon. Permasalahan dibidang produksi, diantaranya (1) peralatan yang digunakan masinh sangat sederhana sehingga kapasitas produksi dan daya saing produk masih rendah, (2) pengetahuan SDM tentang jenis dan manfaat tanaman lokal potensial untuk pengembangan jamu herbal masih terbatas, (3) kreativitas SDM untuk melakukan diversifikasi produk jamu masih rendah. Permasalahan utama dibidang manajemen, diantaranya (1) sistem pengelolaan yang masih menerapkan pola manajemen keluarga sehingga keuntungan usaha home industry belum diketahu secara pasti, (2) promosi dan penjualan dilakukan masih terbatas yaitu dijual secara langsung dan dititipkan pada warung-warung makan di desa dan sekitarnya. tujuan kegiatan PKM ini adalah Peningkatan pemberdayaan mitra kearah ekonomi produktif (pengetahuan, keterampilan dan pendapatan). Metode yang digunakan edukasi, Bimtek, pelatihan dan pendampingan. Hasil kegiatan diukur dengan melihat pengetahuan dan keterampilan mitra. Penilaian menggunakan skala Likert, Selama proses pelatihan dilakukan pengamatan menurut skor $1=$ sangat kurang, $2=$ kurang, $3=$ cukup, $4=$ baik , $5=$ baik sekali. Kata kunci : Sari Pertiwi, Tanaman Herbal, Usadha Bali
\end{abstract}

\begin{abstract}
PKM of the Sari Pertiwi group, which is a traditional herbal medicine industry located in the village of Kelodan, Nyalian village, Banjarangkan sub-district, Klungkung District, Bali is a SIRKUMA herbal medicine made from a mixture of turmeric, ginger, red ginger, kencur, betel leaf, Gotu kola leaf, areca nut, lemon. Problems in the field of production include (1) the equipment used is very simple so that the production capacity and product competitiveness are still low, (2) the knowledge of human resources about the types and benefits of potential local plants for the development of herbal medicine is still limited, (3) the creativity of human resources to carry out product diversification is still low. The main problems in management, including (1) a management system that still applies a family management pattern so that the benefits of a home industry business are not certain, (2) promotions and sales are still limited, namely being sold directly and entrusted to food stalls in the village and the surroundings. The purpose of this PKM activity is to increase partner empowerment towards a productive economy (knowledge, skills, and income). The methods used are education, technical guidance, training, and mentoring. Activity results are measured by looking at the knowledge and skills of partners. The assessment uses a Likert scale. During the training process, observations are made according to a score of $1=$ very poor, $2=$ less, $3=$ sufficient, $4=$ good, $5=$ very good . Keyword : Sari Pertiwi, Herbal Plant, Balinese Traditional Medicine
\end{abstract}




\section{PENDAHULUAN}

\section{ANALISIS SITUASI}

\section{A. Kondisi Mitra}

Industri jamu tradisional merupakan sektor yang inklusif yaitu banyak masyarakat yang bisa mengembangkannya. Salah satunya adalah usaha Sari Pertiwi yang berlokasi di banjar Kelodan desa Nyalian kecamatan Banjarangkan kabupaten Klungkung-Bali. Usaha jamu tradisional Sari Pertiwi ini berdiri sejak tahun 2012 dikordinir oleh Ni Putu Resmiati yang beanggotakan para ibu-ibu semuanya.

Di awal berdirinya, produk jamu yang dijual masih sangat terbatas yaitu jamu olahan kunyit. Seiring dengan berjalannya waktu, tampaknya usaha ini cukup berkembang dimana pada tahun 2019 telah memproduksi aneka jamu tradisional cair yaitu jamu kunyit, jamu daun sirih dan jamu daun piduh. Salah satu produk olahan jamu tradisional produksi Sari Pertiwi yang cukup terkenal dikalangan masyarakat Klungkung dan sekitarnya adalah jamu SIRKUMA yang terbuat dari campuran daun sirih, kunyit dan madu. Manfaat jamu herbal bagi kesehatan telah dikaji melalui hasil penelitian dan juga termuat pada manuskrip Serat Primbon Jampi Jawi jilid 1, yang menyatakan bahwa ekstrak herbal rimpang kunyit memiliki khasiat untuk menjaga stamina, hepatoprotektor, diuretik, antioksidan, antiradang dan antikanker (Hesti Mulyani, Sri Harti Widyastuti, 2016). Disamping itu jahe, kunyit, kapulaga, laos/lengkuas dan kencur sudah dikenal luas sebagai tanaman biofarma (Zamroni Salim, 2017).

Potensi dan peluang usaha jamu tradisional yang dikembangkan oleh Sari Pertiwi cukup prosfektif karena didukung oleh beberapa faktor yaitu (1) lokasi usaha terletak di daerah pegunungan yang berhawa sejuk dengan ketersediaan bahan-bahan alami cukup berlimpah sehingga memberikan peluang dimanfaatkan untuk penganekaragaman produk jamu. (2) lokasi usaha berjarak 12 kilometer dari kota Semarapura sehingga peluang untuk akses penjualan sangat mudah dan lancar, dan (3) meningkatnya minat masyarakat kalangan bawah maupun menengah untuk mengkonsumsi jamu tradisional sebagai minuman favorit karena selain memiliki rasa yang nikmat, aman dikonsumsi juga memberikan manfaat mampu menyegarkan tubuh. Beberapa jenis tanaman rempah berdasarkan usadha Bali sangat potensial sebagai obat tradisional yang banyak dijumpai di daerah lokasi usaha jamu Sari Pertiwi diantaranya banggele, kencur, jahe merah, belimbing wuluh, sirih dan lain-lainnya. Semua jenis rempah tersebut juga telah dikukuhkan sebagai tanaman obat tradisional melalui keputusan Menteri Kesehatan Republik Indonesia nomor HK.01.07/MENKES/187/2017 tentang formularium ramuan obat tradisional Indonesia. Mengingat jamu merupakan bagian dari industri obat tradisional yang mempunyai resiko yang tinggi terhadap kesehatan jika diproduksi menggunakan cara-cara yang tidak hygienis, maka badan Pengawas Obat dan Makanan (BPOM) menyelenggarakan program bapak angkat sehingga pengusaha jamu dan obat herbal dalam proses produksinya memenuhi aturan Cara Pembuatan Obat Tradisional yang Baik (CPOTB) (BPOM RI, 2005). Stikes Buleleng sebagai salah satu perguruan tinggi yang bergerak dibidang pendidikan kesehatan mempunyai kewajiban moral untuk mengedukasi usaha ini agar terus berkembang dengan produkproduk jamu yang sehat serta aman bagi konsumen. Dari program PKM ini diharapkan nantinya mampu menjadikan jamu sebagai obat tradisional sebagai komoditi unggul yang memberikan multi manfaat yaitu berkontribusi terhadap peningkatan kesejahteraan masyarakat dan memberikan peluang kesempatan kerja.

Proses produksi jamu yang dilakukan oleh Sari Pertiwi masih menggunakan peralatan sederhana, diantaranya blander, gentong, tungku, saringan kain, corong, centong, botol. Bahanbahan jamu tersebut dipersiapkan satu hari sebelumnya sedangkan produksi jamunya mulai pagi jam 04.00 sampai jam 06.00 Wita.

Untuk meningkatkan kualitas produk olahan jamu dan kapasitas produksi ada keinginan mitra untuk melakukan upgrading teknologi kearah semi-modern. Untuk itu, melalui program PKM, tim pengusul berencana memberikan bantuan mesin penepung jamu. Mesin penepung ini rencanyanya digunakan untuk mengembangkan produk jamu tradisional dalam bentuk serbuk instan jamu herbal sehingga mempunyai masa simpan lebih lama. Bahan baku yang digunakan untuk memproduksi olahan jamu 
tradisional semuanya berbahan alami sehingga aman bagi konsumen. Observasi langsung pengusul program PKM ke lokasi usaha mitra diperoleh informasi bahan-bahan untuk jamu seperti kunyit, daun sirih, daun piduh, kencur, diambil dari lahan kebunnya sedangkan gula merah, madu, gula batu dan garam dibeli dari pasar tradisional di kota Semarapura. Akan tetapi, jika ada pesanan dalam jumlah yang cukup banyak maka bahan-bahan tersebut juga di beli di pasar tradisional Semarapura. Dalam satu hari, rata-rata jamu yang diproduksi adalah adalah 7 gentong atau sekitar 125 liter dan semuanya laku terjual (Sari Pertiwi saat ini belum menyediakan stok karena lebih dari satu hari rasanya sudah berubah). Penjualan jamu sampai ke konsumen dilakukan pada pagi hari sekitar jam 7 pagi. Strategi penjualannya dilakukan dengan dua cara yaitu (1) menjual secara langsung keliling desa dan sekitarnya, serta (2) jamu dikemas dalam botol kemudian dititipkannya di warung-warung makan. Harga jual untuk semua jenis jamu adalah Rp. 3000 per gelas $(250 \mathrm{~mL})$, kemasan botol dengan harga Rp. 12.000 per botol $(600 \mathrm{ml})$ dan Rp.30.000 perbotol (1500 ml). Usaha jamu Sari Pertiwi berkeinginan mengembangkan produk jamunya dalam bentuk serbuk instan sehingga lebih tahan lama.

Manajemen usaha jamu Sari Pertiwi menggunakan sistem keluarga Administrasi pembukuannya hanya berupa buku catatan hasil penjualan. Promosi produk jamu dilakukan hanya dengan menaruhnya di warung-warung makan yang ada di desa Nyalian dan sekitarnya. Tim pelaksana LPPM Stikes Buleleng melalui skim program kemitraan masyarakat berencana melakukan pelatihan dan pendampingan pada aspek produksi dan manajemen dengan harapan mitra usaha mampu mengembangkan kreativitas dan inovasi produk olahan yang berbasis pada sumber daya lokal.

Kondisi sumber daya yang dimiliki oleh home industry Sari Pertiwi dipilah menjadi dua yaitu sumberdaya manusia/tenaga kerja dan sumberdaya alam/tanaman herbal untuk bahan dasar produksi jamu.

Sumberdaya manusia yang terlibat dalam usaha jamu herbal ini berjumlah 5 orang yang merupakan ibu-ibu putus sekolah yang berasal dari Bali. Rata- rata kualifikasi pendidikannya adalah tamatan SD dan SMP. Pengetahuan yang dimiliki berasal dari warisan orang tuanya dan belajar secara otodidak. Sampai saat ini, SDM yang dimiliki Sari Pertiwi belum pernah mendapatkan pelatihan maupun pendampingan cara pembuatan obat tradisional yang baik (CPOTB). Namun setiap dua bulan sekali pemerintah kabupaten Klungkung melalui dinas kesehatan Klungkung melakukan kunjungan kelokasi mitra untuk memantau keamanan produk jamunya. Obat tradisional termasuk jamu yang dikonsumsi oleh masyarakat luas haruslah didalam penyediaan bahan baku dan produk jadinya memenuhi standar mutu seperti yang termuat dalam Peraturan kepala BPOM Republik Indonesia nomor 12 tahun 2014 tentang persyaratan mutu obat tradisional. Untuk itu, persoalan SDM menjadi hal yang harus perlu diupgrade terutama pada aspek pengetahuan kekinian tentang pemanfaatan tanaman herbal untuk jamu, penguasaan IPTEK tentang produksi jamu, penciptaan daya kreativitas untuk diversifikasi produk dan pengelolaan usaha berbasis IT. Sumber daya alam terutama sumber bahan-bahan untuk membuat jamu sebagian diambil dari kebun sendiri dan sebagian lagi biasanya dibeli dipasar tradisional kota Semarapura. Bahan-bahan seperti kunyit, daun sirih, daun piduh, kencur diperoleh dari lahan kebunnya. Persoalan suplay bahan baku dasar untuk produksi jamu herbal tampaknya tidak menjadi kendala karena kondisi alam pegunungan tempat lokasi usaha banyak tumbuh tanaman-tanaman potensial untuk jamu. 
Jurnal Perempuan dan Anak Indonesia

Permasalahan Mitra

Tabel 1. Permasalahan prioritas usaha mitra

\begin{tabular}{|c|c|}
\hline Aspek masalah & Permasalahan Prioritas \\
\hline Bidang produksi & $\begin{array}{l}\text { 1. Terbatasnya pengetahuan sumberdaya manusia mitra untuk } \\
\text { memproduksi jamu masih sesuai aturan cara pembuatan obat } \\
\text { tradisional yang baik (CPOTB). Dampaknya ada keraguan } \\
\text { konsumen karena kehiginiesan dan keamanan produk masih } \\
\text { diragukan. } \\
\text { 2. Kurangnya pengetahuan, kreativitas dan inovasi SDM dalam } \\
\text { memanfaatkan tanaman herbal usadha Bali untuk melakukan } \\
\text { pengembangan produk jamu sehat. Dampaknya jenis jamu yang } \\
\text { dihasilkan masih terbatas. } \\
\text { 3. Peralatan produksi jamu masih menggunakan pola tradisional. } \\
\text { Dampaknya daya saing produk masih rendah dan kapasitas produksi } \\
\text { terbatas. } \\
\text { 4. Kurangnya kreativitas mitra untuk meningkatkan nilai kemasan } \\
\text { produk. Dampaknya daya saing produk rendah dan daya tarik } \\
\text { konsumen kurang karena penampilan kemasan kurang menarik }\end{array}$ \\
\hline Bidang manajemen & $\begin{array}{l}\text { 1. Administrasi keuangan belum tertata dengan } \\
\text { Dampaknya omzet usaha tidak diketahui secara pasti. } \\
\text { 2. Pola promosi dan manajemen pemasaran produk masih terbatas. } \\
\text { Dampaknya peminat/pembeli masih lokalistik. } \\
\text { 3. Pengelolaan usaha jamu tentang perencanaan strategi bisnis masih } \\
\text { lemah. Dampaknya pengembangan usaha jamu berjalan lambat. }\end{array}$ \\
\hline
\end{tabular}

\section{Tujuan dan Manfaat Kegiatan}

Berdasarkan hasil analisis situasi dan permasalahan yang berhasil diidentifikasi, maka tujuan kegiatan PKM ini adalah Peningkatan pemberdayaan mitra kearah ekonomi produktif (pengetahuan, keterampilan dan pendapatan).

\section{METODE PELAKSANAAN Sasaran kegiatan}

Khalayak sasaran yang dituju adalah Kelompok Usaha Jamu. Tempat yang dipilih adalah di Desa Nyalian, Kecamatan Banjarangkan, Klungkung Bali. Kegitan sosialisasi ini memiliki relevansi dengan kebutuhan masyarakat di lapangan.

\section{Lokasi Kegiatan}

Kegiatan PKM ini dilaksanakan di rumah Ketua Tim Penggerak yang beralamat di Desa Nyalian Kecamatan Banjarangkan Kabupaten Klungkung.

\section{Metode yang digunakan}

Metode-metode penerapan Ipteks yang digunakan diantaranya adalah edukasi, Bimtek, pelatihan dan pendampingan, introduksi Ipteks, dan kombinasi dari dua atau lebih metode sesuai dengan kekomplekan kegiatan. Deskripsi masalah, solusi dan metode pelaksanaan kegiatan yang disepakati oleh mitra program sebagai solusi untuk memecahkan permasalahan disajikan pada Tabel 2 dibawah ini. 
Tabel 2. Deskripsi masalah, solusi dan metode pelaksanaan

\begin{tabular}{|c|c|c|}
\hline Permasalahan & Solusi & Metode Pelaksanaan \\
\hline \multicolumn{3}{|c|}{ Permasalahan pada bidang produksi } \\
\hline $\begin{array}{l}\text { Terbatasnya pengetahuan } \\
\text { sumberdaya manusia mitra } \\
\text { untuk memproduksi jamu } \\
\text { masih sesuai aturan cara } \\
\text { pembuatan obat tradisional } \\
\text { yang baik (CPOTB). }\end{array}$ & $\begin{array}{l}\text { - Meningkatkan pengetahuan } \\
\text { SDM mitra tentang cara } \\
\text { pembuatan jamu tradisional } \\
\text { yang baik sesuai aturan BPOM }\end{array}$ & $\begin{array}{llr}\text { - } & \text { Bimtek tentang cara } \\
\text { pembuatan } & \text { jamu } \\
\text { tradisional yang baik } & \end{array}$ \\
\hline $\begin{array}{l}\text { Kurangnya pengetahuan, } \\
\text { kreativitas dan inovasi SDM } \\
\text { dalam memanfaatkan tanaman } \\
\text { herbal usadha Bali } \\
\text { untuk melakukan pengembangan } \\
\text { produk jamu sehat. }\end{array}$ & $\begin{array}{l}\text { - Edukasi pemanfaatan } \\
\text { tanaman lokal potensial dan } \\
\text { fungsinya dalam } \\
\text { penganekaragaman produk } \\
\text { - Diversifikasi produk jamu } \\
\text { (jamu cair dan jamu serbuk) } \\
\text { dengan memanfaatkan bahan } \\
\text { lokal }\end{array}$ & $\begin{array}{l}\text { - Pengenalan tanaman lokal } \\
\text { potensial sebagai bahan jamu } \\
\text { berdasarkan usadha Bali } \\
\text { - Pelatihan pembuatan jamu } \\
\text { serbuk instan dari bahan lokal } \\
\text { - Pelatihan pembuatan jamu } \\
\text { cair dari bahan lokal }\end{array}$ \\
\hline $\begin{array}{l}\text { Kapasitas produksi terbatas } \\
\text { dan daya saing produk jamu } \\
\text { masih rendah karena peralatan } \\
\text { produksi jamu masih } \\
\text { menggunakan pola tradisional }\end{array}$ & $\begin{array}{l}\text { - Upgrading peralatan dan } \\
\text { teknologi jamu }\end{array}$ & $\begin{array}{l}\text { - Pemberian bantuan mesin } \\
\text { penepung bahan jamu serbuk } \\
\text { instan untuk meningkatkan } \\
\text { kapasitas produksi dan daya } \\
\text { saing produk. }\end{array}$ \\
\hline \multicolumn{3}{|c|}{ - Permasalahan pada bidang manajemen dan pemasaran } \\
\hline $\begin{array}{l}\text { Tampilan kemasan produk } \\
\text { kurang menarik dan tidak } \\
\text { tersedianya informasi bahan } \\
\text { baku pembuat produk dan fungsi } \\
\text { produk }\end{array}$ & $\begin{array}{l}\text { - Merancang kemasan yang } \\
\text { menarik disertai labelisasi } \\
\text { produk yang berisikan } \\
\text { informasi bahan baku yang } \\
\text { digunakan }\end{array}$ & $\begin{array}{l}\text { - Pelatihan dan pendampingan } \\
\text { pembuatan kemasan dan } \\
\text { labelisasi produk }\end{array}$ \\
\hline $\begin{array}{l}\text { Belum adanya pembukuan yang } \\
\text { baik, sehingga tidak tahu } \\
\text { persis } \\
\text { keuntungan yang diperoleh }\end{array}$ & $\begin{array}{l}\text { - Perbaikan sistem administrasi } \\
\text { usaha }\end{array}$ & $\begin{array}{l}\text { - Bimtek sistem administrasi } \\
\text { dan keuangan usaha }\end{array}$ \\
\hline $\begin{array}{l}\text { Rendahnya nilai penjualan dan } \\
\text { keuntungan mitra produk akibat } \\
\text { kurangnya promosi dan } \\
\text { pemasaran }\end{array}$ & $\begin{array}{l}\text { - Memperluas dan memperbaiki } \\
\text { strategi promosi dan pemasaran }\end{array}$ & $\begin{array}{l}\text { - Edukasi strategi promosi dan } \\
\text { pemasaran produk } \\
\text { - Mempromosikan produk } \\
\text { secara online/media sosial } \\
\text { - Pengenalan produk jamu ke } \\
\text { supermarket }\end{array}$ \\
\hline
\end{tabular}




\section{HASIL DAN PEMBAHASAN}

Pada tahap awal tim PKM melakukan koordinasi dengan Ketua Tim Mitra yaitu Ni Putu Resmiati untuk mempersiapkan kegiatan yang akan dilaksanakan terkait bahan-bahan yang akan digunakan. Dan tim PKM mempersiapkan materi pelatihan dan bantuan alat kristalisasi jamu.

Pelaksanaan kegiatan pertama dengan memberikan bantuan alat kristalisasi jamu sekaligus penyuluhan tentang Pengenalan tanaman lokal potensial sebagai bahan jamu berdasarkan usadha Bali.

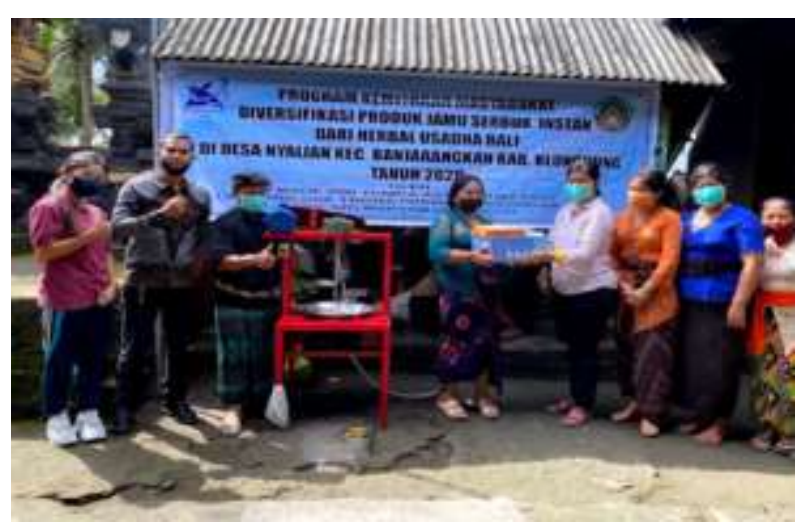

Gambar 1. Penyerahan alat

Tim PKM memberikan edukasi dan demonstrasi pembuatan jamu serbuk dan mengenalkan tanaman lokal potensial sebagai bahan jamu berdasarkan usaha Bali seperti kunyit, temulawak, jahe merah, kencur, daun sirih, daun pegagan, buah pinang, lemon.

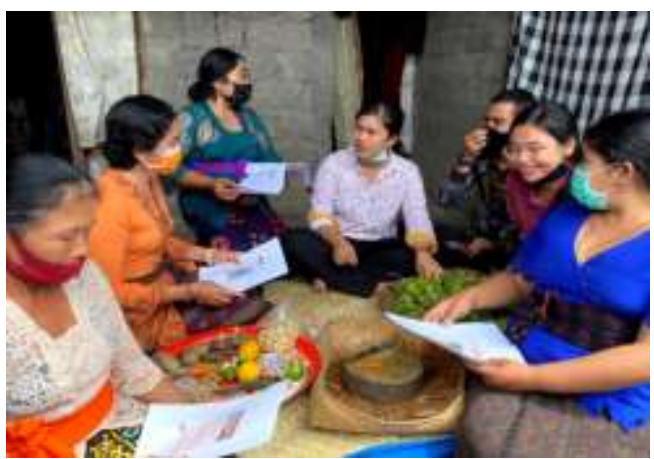

Gambar 2. Edukasi pengenalan tanaman lokal

Kegiatan kedua yaitu pelatihan pembuatan jamu cair. Pada proses ini semua bahan-bahan seperti kunyit, temulawak, jahe merah, kencur, daun sirih, daun pegagan, buah pinang, lemon diblender jadi satu lalu disaring dan dimasak menggunakan tungku yang dimasak selama 1 jam dan ditambahkan gula aren dan gula batu secukupnya. Pembuatan jamu yang baik dan benar sesuai dengan aturan kemenkes dimana jamu cair yang segar sebaiknya untuk dikonsumsi satu hari. Namu dapat juga disimpan dikulkas (maksimal 2-3 hari) (RI, 2015).

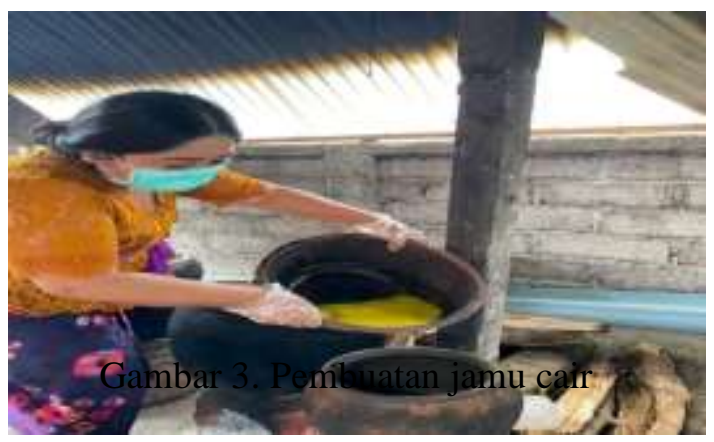

Kegiatan ketiga yaitu pembuatan jamu serbuk. Pada tahap ini kegiatan hampir sama dengan pembuatan jamu serbuk hanya saja proses nya menggunakan alat kristalisasi. Setelah semua bahan diblender dan disaring lalu di panaskan menggunakan alat kristalisasi dan menambahkan gula secukupnya. Pada proses granulasi/kristalisasi secara konvensional memerlukan adanya penambahan gula sebagai inti kristalnya (Handayani et al., 2014). Setelah menjadi Kristal jamu diangkat dan diblender untuk mendapatkan jamu yang halus dan dikemas menggunakan plastik yang sudah diberikan label Sirkuma dan ditimbang agar kemasannya sama satu dengan yang lain.
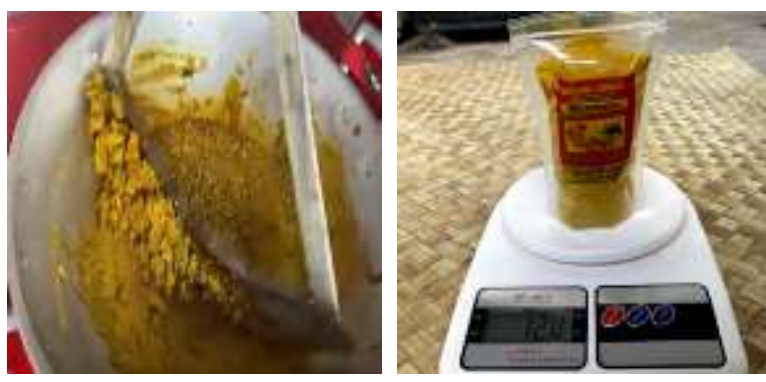

Gambar 4. Proses Kristalisasi dan pengemasan

Kegiatan keempat yaitu bimtek sistem administrasi dan keuangan usaha dan mempromosikan produk secara online/media sosial. Saat ini Jamu Sirkuma sudah dipasarkan secara online yaitu melalui Tokopedia dengan alamat "Sirkuma Herbal", media social facebook (Gambar 6) 


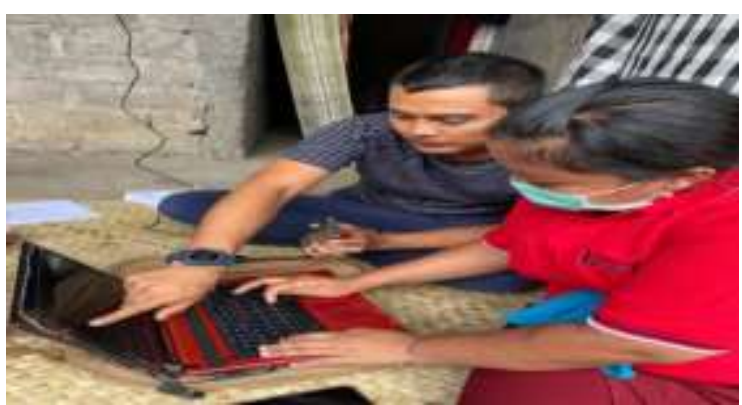

Gambar 5. Pelatihan administrasi keuangan

Selama proses pelatihan dilakukan pengamatan aktivitas peserta pelatihan selama mengikuti pelatihan. Penilaian menggunakan skala Likert, Selama proses pelatihan dilakukan pengamatan menurut skor 1 = sangat kurang, 2 = kurang, $3=$ cukup, $4=$ baik , $5=$ baik sekali. Di bawah ini adalah hasil angket pengetahuan dan observasi untuk kegiatan pembuatan jamu serbuk. Hasil evaluasi kegiatan disajikan dalam Tabel 3 dan 4

Gambar 6. Pemasaran Produk

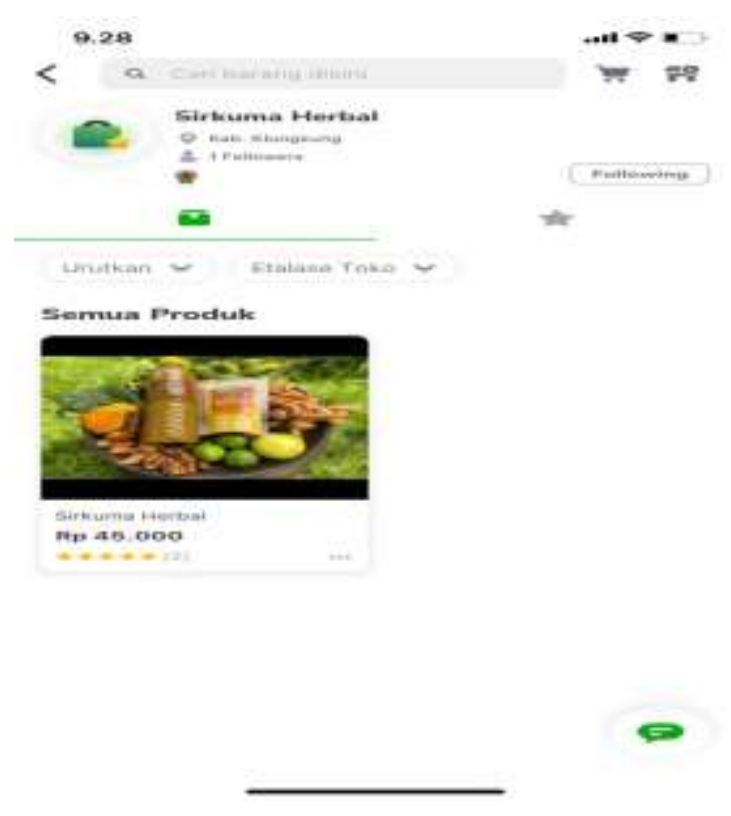


Tabel 3. Hasil Evaluasi Pengenalan tanaman lokal

\begin{tabular}{|c|l|c|c|c|c|c|}
\hline No & \multicolumn{1}{|c|}{ Komponen yang diamati } & \multicolumn{5}{|c|}{ Skor Penilai } \\
\hline 1 & Jenis-jenis tanaman local & 4 & 3 & 4 & 4 & 4 \\
\hline 2 & Manfaat bahan-bahan lokal & 4 & 4 & 4 & 3 & 4 \\
\hline
\end{tabular}

Tabel 4. Hasil Evaluasi Keterampilan Pembuatan jamu serbuk

\begin{tabular}{|c|l|c|c|c|c|c|}
\hline No & \multicolumn{1}{|c|}{ Komponen yang diamati } & \multicolumn{5}{c|}{ Skor Penilai } \\
\hline 1 & Mencuci bahan jamu & 4 & 3 & 4 & 4 & 4 \\
\hline 2 & $\begin{array}{l}\text { Memotong bahan dengan pisau } \\
\text { sehingga berukuran kecil }\end{array}$ & 4 & 4 & 4 & 3 & 4 \\
\hline 3 & $\begin{array}{l}\text { Menghaluskan potongan yang telah } \\
\text { dipotong dengan blender }\end{array}$ & 4 & 4 & 3 & 4 & 4 \\
\hline 4 & $\begin{array}{l}\text { Menyaring hasil blenderan } \\
\text { sehingga diperoleh ekstrak jamu }\end{array}$ & 4 & 4 & 4 & 4 & 3 \\
\hline 5 & $\begin{array}{l}\text { Memanaskan ekstrak jamu dalam } \\
\text { wajan sambil diaduk sampai } \\
\text { diperoleh serbuk jamu }\end{array}$ & 4 & 4 & 4 & 4 & 4 \\
\hline 6 & $\begin{array}{l}\text { Mengayak serbuk jamu yang } \\
\text { diperoleh sehingga diperoleh } \\
\text { serbuk yang halus }\end{array}$ & 4 & 4 & 4 & 4 & 4 \\
\hline
\end{tabular}

Sumber (Ismono et al., 2018)

\section{KESIMPULAN DAN SARAN}

Kegiatan PKM ini telah meningkatkan pemahaman dan pengetahuan ibu-ibu kelompok Sari Pertiwi tentang Pengenalan tanaman lokal potensial sebagai bahan jamu berdasarkan usadha Bali.

Pengingkatan Keterampilan dalam pembuatan jamu serbuk dalam hal mencuci, memotong, menghaluskan potongan, menyaring, memanaskan serta mengayak serbuk jamu.

Peningkatan pendapatan ditandai dengan dengan beberapa pembeli sudah membeli melalui tokopedia dan beberapa supermarket dan warung kecil yang terus melakukan orderan jamu baik jamu cair maupun jamu serbuk.

\section{Saran}

Tetap dilakukanya pendampingan dan monitoring kegiatan secara berkesinambungan agar ibu-ibu kelompok Sari Pertiwi benar-benar melaksanakan pembuatan jamu sesuai dengan aturan Kemekes RI.

\section{UCAPAN TERIMA KASIH}

1. Deputi Bidang Penguatan Riset dan Pengembangan Kementerian Riset dan Teknologi/ Badan Riset dan Inovasi
Nasional Nomor : SP DIPA042.06.1.401516/2019 Tanggal 20

Desember 2019

2. LLDIKTI Wilayah VIII Bali Nusra

3. Ketua STIKes Buleleng, yang telah memberikan motivasi dan dukungan selama kegiatan PKM yang telah dilakukan.

4. Ibu-Ibu kelompok Sari Pertiwi yang sangat kooperatif saat kegiatan berlangsung.

5. Mahasiswa yang terlibat dalam Kegiatan PKM ini.

\section{DAFTAR PUSTAKA}

BPOM RI. (2005). Cara Pembuatan Obat Yang Baik. Badan Pengawas Obat Dan Makanan, 53, 1689-1699. https://doi.org/10.1017/CBO97811074153 24.004

Handayani, D., Ikhsan, D., \& Ardiansari, A. (2014). IbM . Keompok Industri Serbuk Instan Jamu dan Minuman Kesehatan di Ungaran. 10(02).

Hesti Mulyani, Sri Harti Widyastuti, dan V. I. E. (2016). Tumbuhan Herbal Sebagai Jamu Pengobatan Tradisional Terhadap Penyakit 
Jurnal Perempuan dan Anak Indonesia

dalam Serat Primbon Jawi Jilid 1 . Penelitian Humaniora, 2, 73-91.

Ismono, I., Suyatno, S., \& Hidajati, N. (2018). Pelatihan Pembuatan Serbuk Minuman Herbal Instan Untuk Warga Desa Jajar, Kecamatan Talun, Kabupaten Blitar. Jurnal ABDI, 3(2), 76 . https://doi.org/10.26740/ja.v3n2.p76-83

RI, K. (2015). Pembuatan Jamu Segar yang Baik dan Benar. https://doi.org/10.1017/CBO97811074153 24.004

Zamroni Salim, E. M. (2017). Tanaman Obat. Badan Pengkajian Dan Pengembangan Perdagangan Kementerian Perdagangan Republik Indonesia. https://doi.org/10.7748/ldp.5.4.28.s16 